\title{
Milliequivalent per Kilogram per Hour
}

National Cancer Institute

\section{Source}

National Cancer Institute. Milliequivalent per Kilogram per Hour. NCI Thesaurus. Code C66964.

A dose calculation unit expressed in milliequivalent(s) of substance per one kilogram of body mass administered per unit of time equal to one hour. 